\title{
Exploring the Protective and Promotive Effects of School Connectedness on the Relation between Psychological Health Risk and Problem Behaviors/Experiences
}

\author{
Michael Furlong (Corresponding author) \\ Department of Counseling, Clinical, and School Psychology, Gevirtz Graduate School of Education \\ University of California Santa Barbara, Santa Barbara, CA 93110, USA \\ Tel: 1-805-893-3375 E-mail: mfurlong@education.ucsb.edu \\ Jill Sharkey \\ Department of Counseling, Clinical, and School Psychology, Gevirtz Graduate School of Education \\ University of California Santa Barbara, Santa Barbara, CA 93110, USA \\ Tel: 1-805-893-3375 E-mail: jsharkey@education.ucsb.edu \\ Matt Quirk \\ Department of Counseling, Clinical, and School Psychology, Gevirtz Graduate School of Education \\ University of California Santa Barbara, Santa Barbara, CA 93110, USA \\ Tel: 1-805-893-3375 E-mail: mquirk@education.ucsb.edu \\ Erin Dowdy \\ Department of Counseling, Clinical, and School Psychology, Gevirtz Graduate School of Education \\ University of California Santa Barbara, Santa Barbara, CA 93110, USA \\ Tel: 1-805-893-3375 E-mail: edowdy@education.ucsb.edu
}

Received: October 28, 2011

Accepted: November 22, $2011 \quad$ Published: December 30, 2011

doi:10.5539/jedp.v1n1p18

URL: http://dx.doi.org/10.5539/jedp.v1n1p18

\begin{abstract}
The broad construct of school connectedness has been identified as a developmental protective factor due to its association with lower involvement in a variety of problem behaviors. However, resilience research differentiates between protective (lower frequency of problem behaviors primarily in the presence of high risk) and promotive (lower frequency of problem behaviors primarily in conditions of low risk) developmental influences, and this has been an understudied aspect of school connectedness. This study examined the potential protective and promotive influences of school connectedness in a sample of 3,220 students in Grades 8, 10, and 12 from four California school districts. These youths completed self-reports of their psychological health risk, perceptions of school connectedness, and involvement in problem behaviors/experiences. Taking a person-focused data analysis approach, a series of multinomial logistic regressions found that although school connectedness was protective for involvement in problem behaviors/experiences, more support was found for its promotive influences. Implications for research and practice are discussed.
\end{abstract}

Keywords: Protective factor, Promotive factor, Resilience, School connectedness, Psychological health risk, Developmental risk, Problem behaviors

\section{Introduction}

Interpersonal connectedness has been explored as a positive force in youth across diverse fields of study 
including education, health, sociology, and psychology (Barber \& Schluterman, 2008) and "research has taught us that second only to family, school is the most important stabilizing force in the lives of young people" (Blum, 2005 , p. 1). Interest in students' perceptions of the quality of their interpersonal relations with adults at school has origins in delinquency research (Hirschi, 1969). Drawing on social bonding theory, this line of research suggested that youth may follow and comply with rules because they are bonded to people and institutions; that is, youth comply with social norms at least in part because it is a way to maintain positive relationships with adults whom they value. Considered from this social bonding perspective, school connectedness has both cognitive and affective elements because it involves the belief by students that adults in their schools care about them and their learning (Blum \& Libby, 2004). School connectedness is also informed by attachment theory, in that early interactions between children and caregivers influence the quality of future relationships (Sroufe, 2005). Studies have demonstrated that school connectedness involves attachment to teachers and to schools as social institutions (Cernkovich \& Giordano, 1992) and has been defined as, "the belief by students that adults and peers in the school care about their learning as well as about them as individuals" (Centers for Disease Control, 2009, p. 3). From the first day students enter school, there are numerous opportunities for social involvement that are further influenced by family, peer, and community interactions (Maddox \& Prinz, 2003). Consequently, connectedness is identified as an important factor influencing development. Youth who report higher levels of school connectedness are less likely to engage in problem behaviors such as substance use and delinquency (Blum 2005), to experience depression and other types of diminished psychological health (Mylant, Ide, Cuevas, \& Meehan, 2002), and are more likely to drop out of school (Archambault, Janosz, Fallu', \& Pagani, 2006).

\subsection{Connectedness and Problem Behaviors}

Efforts to bolster school connectedness are supported by a substantial body of research showing its association with reduced involvement in problem behaviors in adolescents (Barber \& Schluterman, 2008; Centers for Disease Control and Prevention [CDC], 2009). Much of this research, however, has described school connectedness as a "protective" factor because of its negative association with self-reported involvement in substance use, aggression, and other forms of problem behaviors. The theoretical linkage of school connectedness to resilience theory by use of the term "protective factor" assumes that school connectedness reduces the odds of involvement in problem behaviors among youth experiencing previous developmental risks, but without necessarily testing it as such. Efforts to understand the impact of school connectedness to date have not sufficiently explored the important distinction between protective and promotive influences and have not had a balanced focus between risk and protective influences (Guerra, \& Bradshaw, 2008). To contribute to the further exploration of the influences of school connectedness on development, we first describe the protective-promotive factor distinction in more detail drawing on resilience research (e.g., Masten et al., 2005), and then investigate the relations among school connectedness, psychological health risk, and other problem behaviors/experiences.

\subsection{Resilience and School Connectedness}

Risk and resilience research models explain the promotive-protective distinction regarding how school connectedness might impact the development of behavioral difficulties. In particular, research describes differing developmental pathways whereby children, despite having similar risk, may have dissimilar outcomes. For example, in a prospective study, Masten et al. (2005) identified a negative developmental cascade pattern associated with early childhood externalizing problems that contributed to later academic difficulties in adolescence and ultimately led to internalizing problems in early adulthood. However, despite the potential for such negative developmental cascade trajectories, many vulnerable children do not develop substantial psychological problems later in their lives (Masten \& O'Dougherty Wright, 2010). The construct of resilience has been used to describe this process by which children either achieve positive outcomes or avoid negative outcomes despite having experiences that are empirically associated with vulnerability for later development of psychopathology (Luthar, 2006; Rutter, 1987). What may be overlooked is that resilience necessarily involves exposure to risk factors, which are characteristics of the individual or their socio-ecological contexts that are statistically related to an increased likelihood for problematic developmental outcomes (Masten \& Coatsworth, 1998).

According to resilience theory, protective factors are characteristics of the individual or their life contexts that interact with risk factors to "protect" or "buffer" against negative developmental outcomes (Rutter, 1987). These protective factors predict adaptive outcomes more strongly for youth at risk than youths not at risk, necessitating the presence of risk in order for protection to take place (Rutter, 1987). The potential for resilience suggests that there may not be direct causal pathways leading to outcomes, but rather, various protective factors 
can influence students' reactions to, and susceptibility toward, risk factors (Mash \& Dozois, 1996).

The literature has inaccurately called school connectedness a protective factor only because of its empirical correlation with lower involvement in problem behaviors (CDC, 2009). Among the earliest, most cited, and influential works about school connectedness, Resnick et al. (1997) specifically used the term "protecting from harm" in the title of their article. When discussing the results of their National Longitudinal Study of Adolescent Health (ADD Health) study, Resnick et al. (1997) stated their results demonstrated the protective impact of school connectedness on problematic outcomes because students with higher school connectedness were less likely to engage in (and thereby be protected from) the negative outcomes. However, the Resnick et al. (1997) study did not examine the relation between connectedness and previous risk status. According to resilience theory, to be "protective," connectedness needs to show its influence in the presence of known risks, such as experiencing symptoms of behavioral or emotional problems. As the Resnick et al. (1997) analysis was conducted with a randomized sample of secondary school students, their study was not a pure test of connectedness as a protective factor. The Resnick et al. (1997) study examined a promotive effect of positive developmental outcomes (e.g., decreased substance use) for the general population rather than its protective effect with vulnerable youths.

Recently, Kia-Keating, Dowdy, Morgan, and Noam (2010) and Guerra and Bradshaw (2008) have called for an expanded perspective on risk and resilience when studying health outcomes. They argue that incorporating a positive youth perspective, or the study of factors that promote healthy development for youth, is critical to understanding developmental outcomes. Within this positive youth development framework, school connectedness is considered promotive when youth who perceive school to be highly caring and supportive are more likely to have healthier outcomes than youth who do not perceive school as being highly caring and supportive, regardless of risk. In contrast, the protective nature of school connectedness is demonstrated when a group of students with recognized elevated risk concurrently report lower levels of involvement in problem behaviors/experiences, such as substance use, victimization, and aggression, than students with similar levels of risk but without facilitative levels of school connectedness.

\subsection{Protective and Promotive Effects of School Connectedness}

Several studies have found strong associations between school connectedness and problematic developmental outcomes. For example, in their cross-sectional ADD Health study of 12,118 adolescents, Resnick et al. (1997) reported that school connectedness was significantly negatively associated with emotional distress $(-.43,-.36)$, suicidality $(-.17,-.18)$, and violence $(-.27,-.26)$ for junior high and high school students, respectively. In other research, school connectedness was associated with reductions of substance use (Wang, Matthew, Bellamy, \& James, 2005) and aggression (Brookmeyer, Fanti, \& Henrich, 2006). Although the common interpretation of these findings has been that connectedness has a developmentally "protective" influence, as we've noted, these analyses tested a promotive rather than a protective effect.

A few studies have started to uncover the promotive versus protective role of school connectedness with problem behaviors. A prospective study, also using the ADD Health dataset, examined the relations between students' perceptions of connectedness with caring teachers and participation in problem behaviors (substance use, violence, and suicidal ideation) (McNeely \& Falci, 2004). Students who reported no negative behaviors and high levels of teacher support at Time 1 had a low probability of initiating these problem behaviors at Time 2 . However, for those students who reported that they engaged in these problem behaviors (except for violence) at Time 1, teacher support was not associated with reduction of these behaviors at Time 2, which indicated that this aspect of connectedness functioned more as a promotive than a protective factor. Bearinger, Pettingell, Resnick, and Potthoff (2010) examined weapon carrying among urban American Indian youth who reported using or not using substances. They found that lower versus higher levels of school connections was associated with weapon carrying for substance users $(80 \%$ versus $58 \%)$, but the proportional reduction of weapon carrying was even greater for nonsubstance using youth (31\% to $18 \%)$. Hence this analysis found that school connectedness had both protective and promotive associations with problem behavior.

The potential importance of examining this protective-promotive distinction is that it could enhance understanding of the optimal level of prevention services (universal, secondary, or tertiary) to promote school connectedness. If connectedness functions primarily as a promotive factor, it should be considered a universal-level, positive youth development strategy (Guerra \& Bradshaw, 2008). If connectedness functions more as a protective factor, strategies should be implemented at secondary and tertiary levels of intervention with youth engaging in problem behaviors and experiencing psychological health risks. 


\subsection{Study Purpose}

This study aims to contribute to the literature by considering school connectedness as a protective and promotive factor for youth with psychological health risk. We do this by examining the relation between connectedness and commonly studied problem behaviors (i.e., substance use, victimization, and aggression-related behaviors) among youth who are experiencing the risk factor of symptoms of emotional-behavioral problems. The protective hypothesis would be supported by evidence that school connectedness is associated with less involvement in problem behaviors in the presence of the known risk factor of compromised psychological health. However, we also note that problem behaviors may be associated with other factors such as family or peer influences. Hence, it is unlikely that connectedness could fully buffer the relation between psychological health risk and negative behavior, but may partially buffer this relation. To explore this topic we examine the following research questions: (a) Does school connectedness account for variance in total number of problem behaviors and experiences net of a measure of psychological health risk? and (b) Does school connectedness function as a protective factor, a promotive factor, or both with respect to adolescents' reported problem behaviors?

\section{Method}

\subsection{Participants}

The sample included students enrolled in one of four school districts in a medium-sized city in a semirural area in Southern California that were involved in a Safe Schools/Healthy Students (SS/HS) initiative, which is part of a nationally funded effort in the USA to support collaboration between schools and community agencies to reduce substance use, decrease violence, and to increase the availability of mental health services (Sharkey et al., 2012). A total of 3,220 students in Grades 8, 10, and 12 from 12 secondary schools completed the California Healthy Kids Survey (CHKS). When the CHKS data were processed, each participant's responses were examined for reliability (e.g., 30-day substance could not be more frequent than lifetime use) and validity (e.g., reporting exaggerated substance use, such as daily cocaine use; WestEd, Jerry Bailey, personal communication, May 11, 2008). In all, there were seven response checks - students who did not pass three or more of these checks were considered to have provided implausible responses and were not included in this study. An additional selection criteria for this study was valid responses to all items on the scale measuring school connectedness. When employing these case quality checks, $92.6 \%$ of all cases were retained. The omitted cases were approximately equally distributed across the three grade levels, $\chi^{2}=3.32(2, N=3220), p=.19$, and by gender, $\chi^{2}=1.15(1, N=3220), p=.28$. The final usable sample included 2,982 students. The sample was approximately equally split by gender ( $47.9 \%$ male and $52.1 \%$ female), with more eighth $(36.8 \%)$ and tenth graders $(38.5 \%)$, than twelfth graders $(24.9 \%)$. Most of this sample identified as Hispanic/Latino/a (72.2\%), followed by $18.8 \%$ White, $6.0 \%$ Asian, 3.7\% African American, 3.7\% Native Hawaiian/Pacific Islander, and $3.6 \%$ Native American.

\subsection{Measures}

\subsubsection{Problem Behaviors and Experiences}

The problem behavior items used in this study were taken from the California Healthy Kids Survey (CHKS), an anonymous survey that includes items addressing health behaviors and experiences (WestEd, 2009). The CHKS includes many items from the widely used Youth Risk Behavior Surveillance System (Centers for Disease Control and Prevention, 2011). The CHKS core Module A includes sections about diet and exercise, violence, perceptions of safety, harassment and bullying, and the use of alcohol and other drugs. Five additional modules make up the total CHKS measure, one of which is the Resilience Youth Development Module (RYDM), used in this study. Students' responses were made on a scanable response sheet. The CHKS has been administered to several million students since 1998 .

Twelve items from Module A were used to examine self-reported involvement in problem behaviors and experiences (see Appendix), an approach that has been used in previous research with surveillance surveys examining youth risk and problem behaviors (e.g., Benoit Ratcliff, Jenkins, Reiter-Purtill, Noll, \& Zeller, 2011; Larkin, Frank, Knight, \& Frank, 2007). There were three items for each of the following four domains: (a) substance use (tobacco, alcohol, and marijuana) anywhere in the past 30 days, (b) substance use (tobacco, alcohol, and marijuana) at school is the past 30 days, (c) aggression victimization (physically pushed, rumors spread, and property damaged) at school in the past 12 months, and (d) aggression related experiences (physical fight at school in the past year, brought a gun to campus in the past 30 days, and brought a "weapon" [knife or club] to campus in the past 30 days; see the appendix for wording of the specific items). This total problem behavior index ranged from 0 -12. In this sample, this variable was not normally distributed but its Kurtosis (2.14) and Skewness (1.44) were within acceptable limits for using parametric analysis (Schmider, Ziegler, Danay, 
Beyer, \& Bühner, 2010). The Cronbach's alpha for this index was .75.

\subsubsection{School Connectedness (SC)}

The general construct of school connectedness has been examined across disciplines using related terms such as attachment, engagement, bonding, and belongingness (Furlong, Froh, Muller, \& Gonzalez, 2011). In this study, we used the School Support index from the Resilience Youth Development Module (RYDM) as a measure of school connectedness (SC). The concurrent validity coefficients of the RYDM Student Support (RYDM-SS) measure with the Add Health School Connectedness scale was .47 for males and .48 for females in a sample of more than 400,000 adolescents (Furlong, O'Brennan, \& You, 2011). Hanson and Kim (2007) conducted several factor analyses and bias analyses and found that six items from the original Caring Relationship and High Expectation subscales combined to form the RYDM-SS latent trait (see appendix for the six items comprising this index, scores range from 6-24). The reported alpha coefficient of the RYDM-SS subscale is .89 for both males and females (Furlong, Ritchey, \& O'Brennan, 2009) and in the present sample the Cronbach's alpha coefficient was .90 .

\subsubsection{Psychological Health Risk (PHR)}

As a measure of the students' risk vulnerability we used the Behavior Assessment System for Children-2 Behavioral and Emotional Screening System Student Form (BESS; Kamphaus \& Reynolds, 2007) to assess levels of psychological health risk (PHR). The BESS is a 30-item behavior rating scale screener measuring self-reported levels of symptoms of behavioral, emotional, or mental health problems. Students in Grades 3 through 12 report on their behavioral and emotional functioning using a four-point response scale (never, sometimes, often, almost always). The sum of the item raw scores is transformed to a total $T$ score, in which higher scores reflect more problems: 20-60 suggests a "normal" level of risk, 61-70 suggests an "elevated risk" level of risk, and scores of 71 or higher suggests an "extremely elevated" level of risk. For the present study, students in the elevated and extremely elevated ranges were grouped together, resulting in dichotomized risk-level classification: normal ( $T$-score of 20 to 60 ) or at-risk ( $T$-score of 61 and above).

The psychometric properties of the BESS student form are acceptable, having good split-half reliability (.90-.93) and test-retest reliability (.80). The student form yielded moderate sensitivity (.59), high specificity (.95), moderate positive predictive value (.68), and high negative predictive value (.92). The BESS has moderate correlations with other measures of behavioral and emotional problems: the Achenbach System of Empirically Based Assessment Youth Self-Report (Achenbach \& Rescorla, 2001; $r$ 's $=.66-.77$ ), Conners' Rating Scales (Conners, 1997; $r$ 's $=.51-.68$ ), Children's Depression Inventory (Kovacs, 2001; $r=.51$ ), and the Revised Children's Manifest Anxiety Scale (Reynolds \& Richmond, 2000; $r=.55$ ). Additional psychometric information and information on scale development is available in the manual (Kamphaus \& Reynolds, 2007). Cronbach's alpha on the BESS for this sample was .88.

\subsection{Procedure}

Both passive and active consent was used at the discretion of each school district. District and school coordinators oversaw survey planning and implementation. The survey was administered using a script provided by WestEd (see www.wested.org/chks/pdf/chks_mou_new_0809.pdf for the memorandum of understanding that each district completed prior to administering the $\mathrm{CHKS}$ ). To discourage students discussing their answers and to reduce distractions and interruptions, teachers proctored the administration during a regular 50-min class session in November 2009. The four participating districts had previously successfully administered the CHKS survey five times prior to this data collection cycle.

\subsection{Data Analysis Plan}

Initially, a univariate ANOVA was used to evaluate if gender or grade should be included as covariates in the subsequent analyses. Then, a stepwise multiple regression examined the net contribution of SC in explaining total risks after considering descriptive variables and PHR status. To investigate if SC functioned as a protective or promotive factor, it was necessary to approach the problem from a person-focused perspective; hence, we first formed dichotomous categories (high and low) for SC (based on RYDM-SS scores) and PHR (based on BESS scores). Low PHR were $T$ scores $\leq 60$ on the BESS, which are considered to be in the normal range and high PHR scores were $T$ scores $\geq 61$, which are considered to represent elevated mental health risk (Dowdy et al., 2011). The levels of SC were taken from a CHKS-RYDM normative study (Furlong et al., 2009). Following procedures used by Suldo and colleagues (Suldo \& Shaffer, 2008; Suldo, Thaliji, \& Ferron, 2011), high SC scores were above the $70^{\text {th }}$ percentile (raw scores of 20-24) with scores of 19 or lower placed in the low SC range. 
Crossing the BESS $T$ score with the SC score formed four logical high-low pattern groups: (a) Low PHR - Low SC; (b) Low PHR - High SC (students who could potentially most experience the promotive influences of SC); (c) High PHR - Low SC (students with the most mental health risk); and (d) High PHR - High SC (students who report mental health risk who could experience the protective influences of SC). Figure 1 shows these four groups and their protective and promotive relations with respect to school connectedness. Multinomial logistic regressions evaluated differences across these four groups on each of the 12 problem behaviors/experiences included in the total problem behavior index. Because 12 individual tests were run, the $p$-level for these analyses was set to $.004(.05 / 12)$ using Bonferroni's procedure. The comparison group for these analyses was the High PHR - High SC (protective potential) group. Our general hypothesis is that the odds of a student engaging in any of the 12 problem behaviors/experiences will be significantly associated with the risk-support groups, with the protective potential group (High PHR - High SC) reporting significantly higher rates than the promotive potential group (Low PHR - High SC), but lower rates than the high-risk group (High PHR - Low SC).

\section{Results}

\subsection{Descriptive Findings}

Students exhibited a typical range of PHR, with normally distributed BESS scores in the expected range $\left(M_{T \text { score }}\right.$ $=51.76 ; S D=11.09)$. The mean level of $\mathrm{SC}$ reported across the total sample was $17.79(S D=4.26)$ and, on average, students reported 2-3 out of 12 problem behaviors/experiences $(M=2.20, S D=2.32)$. Students' PHR, $\mathrm{SC}$, and problem behaviors/experiences were all significantly correlated. As expected, PHR was negatively related with SC $(r=-.36, p<.001)$ and positively related with problem behaviors/experiences $(r=.43, p<.001)$. In addition, $\mathrm{SC}$ was negatively correlated with problem behaviors/experiences $(r=-.22, p<.001)$. Thus, students who perceived lower levels of SC were more likely to report higher levels of PHR and a higher number of problem behaviors/experiences.

Following the data analysis plan and as part of the descriptive analysis, students were placed into one of four groups based on their PHR and SC ratings: (a) High PHR - High SC $(n=150,5.0 \%)$, (b) High PHR - Low SC $(n=554,18.6 \%)$, (c) Low PHR - High SC $(n=965,32.4 \%)$, and (d) Low PHR - Low SC $(n=1313,44.0 \%)$. Next, a series of 12 chi-square tests of independence was used to examine associations between PHR - SC group membership and the incidence of students' problem behaviors/experiences. Results showed significant differences $(p<.001)$ amongst the four groups of students across 12 problem behaviors/experiences (see Table 1). The general pattern was that the High PHR - Low SC (most at-risk) group reported the highest involvement in problem behaviors, followed in decreasing order by the High PHR - High SC (protective potential), Low PHR - Low SC, and Low PHR - High SC (promotive potential) groups.

\subsection{Psychological Health Risk, School Connectedness and Problem Behaviors/Experiences}

Initially, we examined the association of the demographic variables of gender and grade with students' involvement in problem behaviors and experiences using a 2 (gender) X 3 (grade level) ANOVA using the total problem behavior index (range 0-12) as the dependent variable. The results found a significant main effect for grade with a small effect size, $F(2,2841)=10.07, p<.001$, partial $\eta^{2}=.007$, and a nonsignificant main effect for gender, $F(1,2841)=1.72, p=.109$, partial $\eta^{2}=.001$. The gender by grade interaction was also nonsignificant, $F(2,2841)=1.18, p=.308$, partial $\eta^{2}=.0001$. Post hoc comparisons using Tukey's criterion showed that students in Grade $8(M=2.4, p=.003)$ and Grade $10(M=2.2, p=.003)$ had higher total problem behavior index scores than those in Grade $12(M=1.9)$. Based on this analysis, gender was not included as a variable in subsequent analyses; however, grade level was included as a binary covariate $(0=$ Grade $12,1=$ Grades 8 and 10).

Stepwise multiple regression examined the net contribution of PHR and SC for explaining the variance in students' problem behaviors/experiences, controlling for grade (see Table 2). Grade was entered at Step 1 and explained only $0.3 \%$ of the variance in students' total problem behavior index. Students' PHR was entered in Step 2 and explained an additional $18.5 \%$ of the variance in students' total problem behavior index, $F_{\text {change }}(1$, $2844)=645.17, p<.001$. After controlling for grade and students' PHR levels, SC was added in Step 3 and explained only an additional $0.5 \%$ of the variance in the total problem behavior index, $F_{\text {change }}(1,2843)=19.24$, $p<.001$. The PHR by SC interaction term was entered at Step 4 and only explained an additional $0.6 \%$ of the variance in students' total problem behavior index, $F_{\text {change }}(1,2842)=21.14, p<.001$. In the final model, all predictor variables were significant $(p<.05)$; however, SC and the PHR x SC interaction term only explained $1.1 \%$ of the remaining variance in the problem behavior index after accounting for Grade and PHR. These results indicated a moderate to strong main effect of PHR and a small main effect of SC, with a similarly small but significant interaction. 


\subsection{School Connectedness as a Protective Influence}

To further examine the potential protective nature of SC with respect to adolescents' problem behaviors and experiences, a series of multinomial logistic regressions was conducted using the High PHR - High SC students (protective potential) as the comparison group (setting its values to zero). If SC functions as a protective factor, results would yield odds ratios (OR) significantly greater than 1.0 for the incidence rates of problem behaviors/experiences for the High PHR - Low SC group (most at risk students) when compared with the High PHR - High SC group.

The results of these analyses were mixed (see Table 3). First, there were no significant differences between the High PHR - High SC group and the High PHR - Low SC group in terms of substance use outside of school (ORs ranging from 1.1-1.3, $p>.05$ ). However, the odds of the High PHR - Low SC students (most at risk) using substances at school were significantly greater than the odds of High PHR - High SC students (protective potential) for cigarettes $(\mathrm{OR}=1.8, p<.01)$ and marginally greater for marijuana $(\mathrm{OR}=1.7, p=.05)$. Similar differences were also found in terms of the odds of High PHR - Low SC students experiencing physical victimization at school $(\mathrm{OR}=1.5, p<.05)$, involvement in a physical fight at school $(\mathrm{OR}=1.5, p<.05)$, and the likelihood of bringing a gun to school $(\mathrm{OR}=2.0, p<.05)$. These results suggested that higher levels of $\mathrm{SC}$ were associated with modestly lower odds of problem behaviors and experiences for students with high PHR, particularly for behaviors and experiences in the school setting.

Regardless of SC level, the odds for both groups of Low PHR students' problem behaviors/experiences were significantly lower than the odds for the High PHR - High SC group across all 12 areas (ORs ranging from $0.2-0.7, p<.05)$. In particular, the odds of students from the Low PHR - High SC group using substances (cigarettes, alcohol, and marijuana) at school were 0.2 times the odds for students from the High PHR - High SC group $(p<.001)$, a moderate effect size. Therefore, students' PHR status was more strongly associated than SC across all 12 evaluated problem behaviors/experiences.

\subsection{School Connectedness as a Promotive Influence}

A second set of multinomial logistic regressions was conducted using the Low PHR - High SC students as the comparison group (setting its values to zero) to examine the potential promotive influence of SC. If SC functioned as a promotive factor, results would yield odds for the Low PHR - Low SC students' problem behaviors/experiences to be significantly greater than the odds for students from the Low PHR - High SC group.

The results of this analysis (see Table 4) revealed significantly higher odds for the Low PHR - Low SC group in the areas of substance use outside of school (ORs ranging from 1.4-2.0, $<<.01$ ), substance use at school (ORs ranging from 2.1-2.6, $p<.01$ ), and aggression-related behaviors at school (ORs ranging from 1.6-2.6, $p<.01$ ). However, there were no significant differences found between the groups in terms of victimization at school, with the odds of experiencing relational victimization at school being marginally significant in the opposite direction $(\mathrm{OR}=0.8, p<.05)$.

Similar to the first multinomial regression analysis, PHR was more influential than school connectedness, with both High PHR groups yielding substantially greater odds for problem behaviors/experiences across all 12 areas (ORs ranging from 1.8-10.5, $<.01$ ). However, the combination of High PHR and Low SC was related to the worst outcomes compared to the combination of Low PHR and High SC. In particular, the odds of students from the High PHR - Low SC group smoking cigarettes at school were 10.5 times greater than the odds for the Low PHR - High SC students and the odds for the High PHR - Low SC students bringing a gun to school were 10.4 times higher than the odds for the Low PHR - High SC group, both large effect sizes.

\section{Discussion}

A primary objective of this study was to further explore SC as a protective/promotive factor related to youth developmental outcomes. We examined in- and out-of-school problem behaviors/experiences of adolescents taking into consideration their level of PHR. We found a negative correlation between PHR and SC $(r=-.36)$, which is similar to other studies that have compared emotional distress and SC ( $r=-.45$, McGraw, Moore, Fuller, $\&$ Bates, 2008; $r=-.42$, Wilkinson-Lee, Zhang, Nuno, \& Wilhelm, 2011). More support was found for SC as a promotive developmental influence when the criterion behavior was negative outcomes (i.e., problem behaviors). The lowest levels of involvement in problem behaviors were among those youths who had low PHR and who also reported higher levels of SC. In contrast, only a small effect was found for SC having a protective influence. Youths with elevated PHR, but who reported higher levels of SC, engaged in fewer negative behaviors at school compared to youth with equally high levels of PHR but lower levels of SC.

One of the problem criterion behaviors examined in this study was substance use in school and nonschool 
settings. It is known that comorbidity of substance use and mental health disorders is common, with estimates of between two-thirds and four-fifths of youth with substance use problems having a diagnosable mental health disorder (Hawkins, 2009). Of the various models that seek to explain the co-occurrence of these conditions, one with empirical support is that the onset of a mental health disorder is more likely to precede substance use than vice versa (Libby, Orton, Stover, \& Riggs, 2005). The strong relation between PHR found in this study is consistent with the adolescent comorbidity research. Possible explanations for these findings include, that by the time youth reach adolescence, the factors that place them at risk of experiencing PHR are likely to be complex and encompass various social contexts, with family and peer influences being predominant (Hawkins, 2009). It may be too much to expect that positive relationships with adults at school and a positive orientation to school as an institution would be sufficiently powerful to overcome the detrimental influences of traumatic family and peer experiences. An alternative explanation that merits further investigation is that status of adolescent substance use, PHR, and SC are all affected by other common factors and developmental risks (Hawkins, Catalano, \& Miller, 1992). This study's finding that the ratio of youth identified in the High PHR - Low SC group to those identified in the High PHR - High SC group was 3.7:1 lends support to the common factor model.

Another notable finding was that SC's moderate promotive and modest protective associations were strongest for school-related problem behaviors (such as smoking on school campus), which suggests that students who reported closer interpersonal relationships at school with teachers may have been more likely to temper their on-campus behavior as a way of respecting those relationships. In contrast, teacher behavior may be less likely to affect off-campus problem behaviors, where peer and family influences might be more prominent. This finding is similar to that reported by Wilkinson-Lee et al. (2010) who examined mental health status with respect to having multiple family task obligations, which could become a risk factor if they created excessive demands and stress in the adolescent's life. These authors found that their measure of SC was negatively associated with emotional distress, but only significantly for those youth with three or fewer familial obligations. For those youth with four or more obligations, SC did not buffer emotional distress, which did not support it being characterized as a protective factor against mental health risk.

\subsection{Study Limitations}

In past research, the SC latent construct was most prominently defined in terms of a student's belief that adults at school care for them and support their learning, but this construct has had a history of being used with less-than-desired precision (Blum \& Libbey, 2004). The RYDM-SC measure used in this study clearly retained both the caring relationship element and student beliefs that teachers held high performance expectations for them. However, the SC construct has definitional ambiguity (McNeely \& Falci, 2004) and recently has added elements making it even more complex (Barber \& Schluterman, 2008). For example, the SC model described in "School Connectedness: Strategies for Increasing Protective Factors Among Youth" (CDC, 2009) expanded SC to include three new elements: positive peer support, commitment to education, and positive school environment. As SC has become a more complex construct, some researchers have suggested that it now encompasses elements of the broader construct of student engagement (Appleton, Christenson, \& Furlong, 2008; Griffiths, Lilles, Furlong, \& Sidwha, 2012). Hence, the narrower-band measure used in this study may have provided a limited test of the protective effects of school connectedness as it relates to the problem behaviors/experiences examined. Additional research is recommended that includes a multifactored connectedness measure to further examine its relations with other problematic developmental outcomes.

Another limitation is that all measures used in this study were youth self-reports. Although youth are a good source of information about mental health functioning, measuring elevated mental health risk via parent or teacher reports would enhance future studies. Similarly, the outcomes assessed in this study focused on participation in problem behaviors. As suggested by Guerra and Bradshaw (2008), research needs to also focus on positive, thriving developmental outcomes. This study used cross-sectional data of adolescents in secondary schools and does not generalize to younger children with psychological health risk, for whom school connectedness might have a protective effect. Additional research needs to examine these patterns prospectively and across a broader age span. Finally, this study did not consider school-level influences (e.g., school climate and discipline practices), which could have influenced student self-reports of school connectedness.

\subsection{Implications for Research and Practice}

Although there is evidence that stronger teacher-student relationships are associated with decreased involvement in problem behaviors cross-sectionally (Resnick et al., 1997) and prospectively (Bond et al., 2007; McNeely \& Falci, 2004), these findings may not apply to all youth in the same way we found for youth experiencing emotional and behavioral problem symptoms. There is a need to further examine how SC is related to the onset 
and course of adolescent mental health problems (Shochet, Dadds, Ham, \& Montague, 2006) and to the promotion of psychological well-being (Suldo \& Shaffer, 2008). Investigations examining the differentiation between SC as a protective or promotive factor are important because how researchers and clinicians consider the theoretical foundation of SC will influence both research and clinical practice. By resilience research convention, the term "protective factor" has been used to describe those life conditions or influences present in the lives of groups of children with known developmental risk factors that were associated with decreased incidence of substance use, psychopathology, and other poor developmental outcomes. The results of this study suggest that, at least when PHR is considered, SC functions more as a promotive factor, which enhances the functioning of youth with few risks, more than it buffers against negative outcomes for youth who have elevated risk. In any case, we found that only $20 \%$ of the adolescents with elevated PHR (5.0\% of all students in the study) reported higher levels of SC. Even if SC fully functioned as protective factor, there is great need to bolster the connectedness of students who experience emotional and behavioral challenges. Considered as a promotive factor, the results of this study also suggested that there is a much work to be done to build positive connectedness for all students. The largest group in this study was students with low PHR but without concurrent higher levels of SC (46.1\%). The potential positive effects of SC cannot be fully realized until a majority of students perceive their schools as providing positive and nurturing relationships, regardless of risk experiences.

If connectedness influences development more as a promotive than a protective factor, this has implications for researchers and clinicians. To the extent that the results of this study apply broadly to other populations, it suggests that the balanced risk and resilience perspective offered by Kia-Keating et al. (2011) may be instructive. Their model places more emphasis on early prevention and intervention programs, which would be particularly true if PHR, risk behaviors, and connectedness are all have origins in common risk factors. If so, this suggests that from the earliest days of schooling, efforts are needed to provide contexts for students to interact with adults in ways that consciously aim to help them experience school as a caring and supportive social context (McLaughlin \& Clarke, 2010; Rowe \& Stewart, 2009) (also see Centers for Disease Control and Prevention [2009] and Benard and Slade [2009] for specific strategies to build school connectedness at the primary prevention level). As the findings of this study suggested, a supportive social context has the potential benefit of enhancing the developmental outcomes of all students. At the same time, as the mental health functioning of students is significantly related to problem behaviors, efforts to provide early screening for and response to emerging mental health problems are needed for those youths who experience excessive life stresses and challenges (Dowdy, Furlong, Eklund, Saeki, \& Ritchey, 2010). Such an approach that balances between risk-reduction and the promotion of positive social connections at school may be in order.

\section{References}

Achenbach, T. M., \& Rescorla, L. A. (2001). Manual for the ASEBA school-age forms and profiles. Burlington, VT: University of Vermont, Research Center for Children, Youth, and Families.

Appleton, J. J., Christenson, S. L., \& Furlong, M. J. (2008). Student engagement with school: Critical conceptual and methodological issues of the construct. Psychology in the Schools, 45, 369-386. http://dx.doi.org/10.1002/pits.20303

Archambault, I., Janosz, M., Fallu', J., \& Pagani, L. S. (2006). Student engagement and its relationship with early high school dropout. Journal of Adolescence, 32, 651- 670.

Barber, B. K., \& Schluterman, J. M. (2008). Connectedness in the lives of children and adolescents: A call for greater conceptual clarity. Journal of Adolescent Health, 43, 209-216.

Battistich, V., \& Hom, A. (1997). The relationship between students' sense of their school as a community and their involvement in problem behaviors. American Journal of Public Health, 87, 1997-2001.

Bearinger, L. H., Pettingell, S. L., Resnick, M. D., \& Potthoff, S. J. (2010). Reducing weapon-carrying among urban American Indian young people. Journal of Adolescent Health, 47, 43-50.

Benard, B., \& Slade, S. (2009). Listening to students: Moving from resilience research to youth development practice and school connectedness. In R. Gilman, E. S. Huebner, \& M. J. Furlong (Eds.), Handbook of positive psychology in the schools (pp. 353-370). New York: Routledge.

Benoit Ratcliff, M., Jenkins, T. M., Reiter-Purtill, J., Noll. J. G., \& Zeller, M. H. (2011). Risk-taking behaviors of adolescents with extreme obesity: Normative or not? Pediatrics, 127, 827-834.

Blum, R. (2005). School connectedness: Improving the lives of students. Baltimore, MD: Johns Hopkins Bloomberg School of Public Health. 
Blum, R. W., \& Libbey, H. P. (2004). Wingspread declaration on school connections. Journal of School Health, 74, 233-234.

Bond, L., Butler, H., Thomas, L., Carlin, J., Glover, S., Bowes, G., \& Patton, G. (2007). Social and school connectedness in early secondary school as predictors of late teenage substance use, mental health, and academic outcomes. Journal of Adolescent Health, 40, 357, e9-357.e18.

Brookmeyer, K. A., Fanti, K. A., \& Henrich, C. C. (2006). Schools, parents, and youth violence: A multilevel, ecological analysis. Journal of Clinical Child and Adolescent Psychology, 35, 504-514. http://dx.doi.org/10.1207/s15374424jccp3504_2

Centers for Disease Control and Prevention. (2009). School connectedness: Strategies for increasing protective factors among youth. Atlanta, GA: U.S. Department of Health and Human Services.

Centers for Disease Control and Prevention. (2011). Youth Risk Behavior Surveillance System (YRBSS). Atlanta, GA: U.S. Department of Health and Human Services. Website, [Online] Available: http://www.cdc.gov/HealthyYouth/yrbs/index.htm

Cernkovich, S. A., \& Giordano, P. C. (1992). School bonding, race, and delinquency. Criminology, 30, $261-291$. http://dx.doi.org/10.1111/j.1745-9125.1992.tb01105.x

Conners, C. K. (1997). Conners'Rating Scales-Revised. North Tonawanda, NY: Multi-Health Systems.

Dowdy, E., Furlong, M., Eklund, K., Saeki, E., \& Ritchey, K (2010). Screening for mental health and wellness. In B. Doll, W. Pfohl, \& J. Yoon (Eds.), Handbook of youth prevention science (pp. 70-95). New York: Springer Science.

Dowdy, E., Twyford, J. M., Chin, J. K., DiStefano, C. A., Kamphaus, R. W., \& Mays, K. L. (2011). Factor structure of the BASC-2 behavioral and emotional screening system student form. Psychological Assessment, 23, 379-387.

Furlong, M. J., Froh, J., Muller, M., \& Gonzalez, V. (2011). The role of student engagement in engaged living and psychological and social well-being: The centrality of connectedness/relatedness. Manuscript submitted for publication.

Furlong, M. J., O’Brennan, L., \& You, S. (2011). Psychometric properties of the Add Health School Connectedness Scale for 18 sociocultural groups. Psychology in the Schools, 48, 986-997. [Online] Available: http://onlinelibrary.wiley.com/doi/10.1002/pits.20609/full

Furlong, M. J., Ritchey, K. M., \& O’Brennan, L. M. (2009). Developing norms for the California Resilience Youth Development Module: Internal assets and school resources subscales. California School Psychologist, $14,35-46$. [Online] Available: http://findarticles.com/p/articles/mi_7479/is_200901/ai_n52375541/

Griffiths, A., Lilles, E., Furlong, M. J., \& Sidwha, J. (in press). The relations of adolescent student engagement with troubling and high-risk behaviors. In S. L. Christenson, A. L. Reschly, \& C. Wylie (Eds.), The handbook of research on student engagement. New York: Springer Science.

Guerra, N. G., \& Bradshaw, C. P. (2008). Linking the prevention of problem behaviors and positive youth development: Core competencies for positive youth development and risk prevention. In N. G. Guerra \& C. P. Bradshaw (Eds.), Core competencies to prevent problem behaviors and promote positive youth development. New Directions for Child and Adolescent Development, 122, 1-17.

Hanson, T. L., \& Kim, J. O. (2007). Measuring resilience and youth development: the psychometric properties of the Healthy Kids Survey. (Issues \& Answers Report, REL 2007-No. 034). Washington, DC: U.S. Department of Education, Institute of Education Sciences, National Center for Education Evaluation and Regional Assistance, Regional Educational Laboratory West.

Hawkins, E. H. (2009). A tale of two systems: Co-occurring mental health and substance abuse disorders treatment for adolescents. Annual Review of Psychology, 60, 197-227. http://dx.doi.org/10.1146/annurev.psych.60.110707.163456

Hawkins, J. D., Catalano, R. F., \& Miller, J. Y. (1992). Risk and protective factors for alcohol and other drug problems in adolescence and early adulthood: Implications for substance abuse prevention. Psychological Bulletin, 112, 64-105. http://dx.doi.org/10.1037/0033-2909.112.1.64

Hirschi, T. (1969). Causes of delinquency. Berkeley and Los Angeles, CA: University of California Press.

Kamphaus, R. W., \& Reynolds, C. R. (2007). Behavior Assessment System for Children-Second Edition (BASC-2): Behavioral and Emotional Screening System (BESS). Bloomington, MN: Pearson. 
Kia-Keating, M., Dowdy, E., Morgan, M., \& Noam, G. G. (2011). Protecting and promoting: An integrative conceptual model for healthy development of adolescents. Journal of Adolescent Health, 48, 220-228. http://dx.doi.org/10.1016/j.jadohealth.2010.08.006

Kovacs, M. (2001). Children's Depression Inventory: Manual. North Tonawanda, NY: Multi-Health Systems.

Larkin, E., Frank, J., Knight, K., \& Frank, S. (2007). Health risk behaviors in a unique population - first ring suburban adolescents. Journal of Community Health, 32, 37-55. http://dx.doi.org/10.1007/s10900-006-9028-2

Libby, A. M., Orton, H. D., Stover, S. K., \& Riggs, P. D. (2005). What came first, major depression or substance use disorder? Clinical characteristics and substance use comparing teens in a treatment cohort. Addictive Behavior, 30, 1649-1662. http://dx.doi.org/10.1016/j.addbeh.2005.07.012

Luthar, S. (2006). Resilience in development: A synthesis of research across five decades. In D. Cicchettie, \& D. J. Cohen (Eds.). Developmental psychopathology (Vol 3., pp. 739-795). Hoboken, NJ: Wiley.

Maddox, S. J., \& Prinz, R. J. (2003). School bonding in children and adolescents: Conceptualization, assessment, and associated variables. Clinical Child and Family Psychology Review, 6, 31-49. http://dx.doi.org/10.1023/A:1022214022478

Mash, E. J., \& Dozois, D. J. A. (1996). Child psychopathology: A developmental-systems perspective. In E. J. Mash \& L. G. Terdal (Eds.), Child psychopathology (pp. 3-60). New York: Guilford.

Masten, A. S., \& Coatsworth, J. D. (1998). The development of competence in favorable and unfavorable environments: Lessons from research on successful children. American Psychologist, 53, 205-220. http://dx.doi.org/10.1037//0003-066X.53.2.205

Masten, A. S., Roisman, G. I., Long, J. D., Burt, K. B., Obradovic, J., Riley, J. R., \& Tellegen, A. (2005). Developmental cascades: Linking academic achievement and externalizing and internalizing symptoms over 20 years. Developmental Psychology, 41, 733-746. http://dx.doi.org/10.1037/0012-1649.41.5.73

Masten, A., \& O'Dougherty Wright, M. (2010). Resilience over the lifespan: Developmental perspective on resistance, recovery, and transformation. In J. W. Reich, A. J. Zautra, \& J. S. Hall (Eds.), Handbook of adult resilience (pp. 213-237). New York: Guilford.

McGraw, K., Moore, S., Fuller, A., \& Bates, G. (2008). Family, peer and school connectedness in final year secondary school students. Australian Psychologist, 43, 27-37. http://dx.doi.org/10.1080/00050060701668637

McLaughlin, C., \& Clarke, B. (2010). Relational matters: A review of the impact of school experience on mental health in early adolescence. Educational and Child Psychology. Special Issue: In-School Relationships and their Outcomes, 27, 91-103.

McNeely, C., \& Falci, C. (2004). School connectedness and the transition into and out of health risk behavior among adolescents: A comparison of social belonging and teacher support. Journal of School Health, 74, 284-292. http://dx.doi.org/10.1111/j.1746-1561.2004.tb08285.x

Mylant, M., Ide, B., Cuevas, E., \& Meehan, M. (2002). Adolescent children of alcoholics: Vulnerable or resilient? Journal of the American Psychiatric Nurses Association, 8(2), 57-64. http://dx.doi.org/10.1067/mpn.2002.125037

O’Brennan, L. M., \& Furlong, M. J. (2010). Relations between students' perceptions of school connectedness and peer victimization. Journal of School Violence, 9, 375-391. http://dx.doi.org/10.1080/15388220.2010.509009

Resnick, M. D., Bearman, P. S., Blum, R. W., Bauman, K. E., Harris, K. M., Jones, J., ... Udry, J. R. (1997). Protecting adolescents from harm: Findings from the national longitudinal study of adolescent health. Journal of the American Medical Association, 278, 823-832.

Reynolds, C. R., \& Richmond, B. O. (2000). Revised Children's Manifest Anxiety Scale. Los Angeles, CA: Western Psychological Services.

Rowe, F., \& Stewart, D. (2009). Promoting connectedness through whole-school approaches: A qualitative study. Health Education, 109, 396-413. http://dx.doi.org/10.1108/09654280910984816

Rutter, M. (1987). Psychosocial resilience and protective mechanisms. American Journal of Orthopsychiatry, 57, 316-331. http://dx.doi.org/10.1111/j.1939-0025.1987.tb03541.x

Schmider, E., Ziegler, M., Danay, E., Beyer, L., \& Bühner, M. (2010). Is it really robust? Reinvestigating the robustness of ANOVA against violations of the normal distribution assumption. Methodology: European Journal of Research Methods for the Behavioral and Social Sciences, 6, 147-151. http://dx.doi.org/10.1027/1614-2241/a000016 
Sharkey, J. D., Furlong, M. J., Dowdy, E., Felix, E. D., Grimm, L., \& Ritchey, K. (2012). The United States Safe Schools/Healthy Students Initiative: Turning a national initiative into local action. In S. R. Jimerson, A. B. Nickerson, M. J. Mayer, \& M. J. Furlong (Eds.), The handbook of school violence and school safety: International research and practice (2nd ed.). New York: Routldege.

Shochet, I. M., Dadds, M. R., Ham, D., \& Montague, R. (2006). School connectedness is an underemphasized parameter in adolescent mental health: Results of a community prediction study. Journal of Clinical Child and Adolescent Psychology, 35, 170-179. http://dx.doi.org/10.1207/s15374424jccp3502_1

Sroufe, L. A. (2005). Attachment and development: A prospective, longitudinal study from birth to adulthood. Attachment and Human Development, 7, 349-367. http://dx.doi.org/10.1080/14616730500365928

Suldo, S. M., \& Shaffer, E. J. (2008). Looking beyond psychopathology: The dual-factor model of mental health in youth. School Psychology Review, 37, 52-68. http://dx.doi.org/10.1002/pits.20300

Suldo, S., Thalji, A., \& Ferron, J. (2011). Longitudinal academic outcomes predicted by early adolescents' subjective well-being, psychopathology, and mental health status yielded from a dual factor model. The Journal of Positive Psychology, 6, 17-30. http://dx.doi.org/10.1080/17439760.2010.536774

Wang, M. Q., Matthew, R. F., Bellamy, N., \& James, S. (2005). A structural model of the substance use pathways among minority youth. American Journal of Health Behavior, 29, 531-541.

WestEd. (2009). California Healthy Kids Survey. [Online] Available: http://www.wested.org/cs/chks/print/docs/chks_home.html

Wilkinson-Lee, A. M., Zhang, Q., Nuno, V. L., \& Wilhelm, M. S. (2011). Adolescent emotional distress: The role of family obligations and school connectedness. Journal of Youth and Adolescence, 40, 221-230. http://dx.doi.org/10.1007/s10964-009-9494-9 
Table 1. Association of Psychological Health Risk (PHR) symptoms and School Connectedness (SC) with problem behaviors/experiences for students in grades 8,10 , and 12

\begin{tabular}{|c|c|c|c|c|c|}
\hline $\begin{array}{l}\text { Problem } \\
\text { Behaviors/Experiences }\end{array}$ & $\begin{array}{c}\text { High PHR } \\
\text { Low SC } \\
\text { (high risk) }\end{array}$ & $\begin{array}{l}\text { High PHR } \\
\text { High SC } \\
\text { (protective } \\
\text { potential) }\end{array}$ & $\begin{array}{c}\text { Low PHR } \\
\text { Low SC } \\
\text { (low risk) }\end{array}$ & $\begin{array}{l}\text { Low PHR } \\
\text { High SC } \\
\text { (promotive } \\
\text { potential) }\end{array}$ & $\chi \quad(d f)$ \\
\hline $\begin{array}{l}\text { Substance use } \\
\text { anywhere }\end{array}$ & & & & & \\
\hline 1. Cigarettes ${ }^{a}$ & $26.0 \%(n=554)$ & $24.7 \% \quad(n=150)$ & $12.8 \% \quad(n=1313)$ & $6.8 \% \quad(n=965)$ & $123.67(3,2982)^{\mathrm{c}}$ \\
\hline 2. Alcohol ${ }^{\mathrm{a}}$ & $48.6 \%(n=554)$ & $44.7 \%(n=150)$ & $33.7 \% \quad(n=1313)$ & $26.4 \% \quad(n=965)$ & $83.36(3,2982)^{\mathrm{c}}$ \\
\hline 3. Marijuana $^{a}$ & $32.9 \%(n=554)$ & $26.7 \%(n=150)$ & $16.5 \% \quad(n=1313)$ & $12.2 \%(n=965)$ & $110.44(3,2982)^{\mathrm{c}}$ \\
\hline \multicolumn{6}{|l|}{ Substance use at school } \\
\hline 4. Cigarettes ${ }^{a}$ & $14.4 \%(n=549)$ & $8.7 \%(n=150)$ & $4.0 \% \quad(n=1299)$ & $1.6 \%(n=959)$ & $123.06(3,2957)^{\mathrm{c}}$ \\
\hline 5. Alcohol ${ }^{\mathrm{a}}$ & $21.5 \% \quad(n=553)$ & $16.7 \%(n=150)$ & $8.5 \% \quad(n=1294)$ & $3.8 \%(n=954)$ & $135.25(3,2951)^{\mathrm{c}}$ \\
\hline 6. Marijuana ${ }^{a}$ & $20.0 \% \quad(n=551)$ & $12.8 \%(n=148)$ & $6.7 \% \quad(n=1288)$ & $3.3 \%(n=957)$ & $136.46(3,2994)^{c}$ \\
\hline \multicolumn{6}{|l|}{ Victimization at school } \\
\hline 7. Physical & $45.6 \%(n=551)$ & $36.9 \%(n=149)$ & $25.7 \%(n=1309)$ & $25.2 \%(n=962)$ & $104.70(3,2944)^{\mathrm{c}}$ \\
\hline 8. Relational & $53.3 \%(n=550)$ & $55.7 \% \quad(n=149)$ & $30.1 \%(n=1304)$ & $34.5 \%(n=962)$ & $113.55(3,2965)^{\mathrm{c}}$ \\
\hline 9. Property & $34.5 \%(n=548)$ & $29.5 \%(n=149)$ & $21.1 \%(n=1307)$ & $19.2 \%(n=963)$ & $53.96(3,2967)^{\mathrm{c}}$ \\
\hline \multicolumn{6}{|l|}{$\begin{array}{l}\text { Aggression-related } \\
\text { behaviors at school }\end{array}$} \\
\hline 10. Physical fight & $37.5 \% \quad(n=549)$ & $28.4 \% \quad(n=148)$ & $20.9 \%(n=1310)$ & $14.8 \%(n=961)$ & $122.68(3,2960)^{\mathrm{c}}$ \\
\hline 11. Gun & $14.8 \%(n=549)$ & $8.0 \%(n=150)$ & $4.2 \% \quad(n=1298)$ & $1.7 \%(n=963)$ & $142.99(3,2960)^{\mathrm{c}}$ \\
\hline 12. Other weapon & $18.6 \%(n=552)$ & $20.1 \%(n=149)$ & $10.8 \% \quad(n=1305)$ & $5.3 \%(n=959)$ & $123.87(3,2965)^{\mathrm{c}}$ \\
\hline
\end{tabular}

Note. PHR = Psychological Health Risk from the Behavioral and Emotional Screening System, SC = School Connectedness latent trait from the California Healthy Kids Resilience Youth Development Module School Support index, High PHR = BESS $T$-scores $\geq 61$, Low PHR $=$ BESS $T$-scores $\leq 60$; High SC $=$ Raw scores $\geq 20$, Low $\mathrm{SC}=$ Raw scores $\geq 19$. ${ }^{\mathrm{a}}$ Any use in the past 30 days. ${ }^{\mathrm{b}}$ Two or more weeks of sadness in the past year. ${ }^{\mathrm{c}} p<.001$. 
Table 2. Hierarchal logistic regression predicting problem behaviors/experiences index from grade, Psychological Health Risk (PHR), and School Connectedness (SC) scores

\begin{tabular}{|c|c|c|c|c|c|c|c|c|c|c|c|c|}
\hline \multirow{2}{*}{ Variable } & \multicolumn{3}{|c|}{ Step 1} & \multicolumn{3}{|c|}{ Step 2} & \multicolumn{3}{|c|}{ Step 3} & \multicolumn{3}{|c|}{ Step 4} \\
\hline & $b$ & $S E b$ & $B$ & $b$ & $S E b$ & $B$ & $b$ & $S E b$ & $B$ & $b$ & $S E b$ & $B$ \\
\hline Grade & 0.28 & 0.09 & $0.06 * * *$ & 0.18 & 0.08 & $0.04 *$ & 0.19 & 0.08 & $0.039^{*}$ & .19 & .081 & $.04 *$ \\
\hline PHR & & & & 0.08 & 0.003 & $\begin{array}{l}0.43 * * \\
*\end{array}$ & 0.07 & 0.003 & $0.40 * * *$ & .04 & .009 & $.20 * * *$ \\
\hline $\mathrm{SC}$ & & & & & & & -0.04 & 0.01 & $-0.08 * * *$ & .05 & .022 & $.09^{*}$ \\
\hline PHR x SC & & & & & & & & & & .003 & .001 & $.32 * * *$ \\
\hline$R 2$ & .003 & & & .19 & & & .19 & & & .20 & & \\
\hline$F \Delta R^{2}$ & 9.57 & & & 645.17 & & & 19.24 & & & 21.14 & & \\
\hline
\end{tabular}

Note. PHR $=$ Psychological Health Risk from the Behavioral and Emotional Screening System (BESS), SC = School Connectedness latent trait from the California Healthy Kids Resilience Youth Development Module School Support index. Grade coded as a binary variable $\left(0=12^{\text {th }}\right.$ grade, $1=8^{\text {th }}$ and $10^{\text {th }}$ grades $)$. BESS $T$-score used for this analysis. Univariate correlations of the problem behavior index were .43 with BESS total $T$-score and -.23 with RYDM-SS subscale. ${ }^{*} p<.05 . * * p<.01 . * * * p<.001$.

Table 3. Odds ratios of problem behaviors/experiences by psychological health risk and perceived school connectedness as a protective factor (Hi PHR-Hi SC set to be the comparison group)

\begin{tabular}{|c|c|c|c|c|c|c|c|c|}
\hline & $\begin{array}{c}\text { High PHR } \\
\text { High SC } \\
(n=150) \\
\text { Comparison } \\
\text { group } \\
\text { Protective } \\
\text { potential } \\
\end{array}$ & & $\begin{array}{l}\text { High PHR } \\
\text { Low SC } \\
(n=554)\end{array}$ & & $\begin{array}{l}\text { Low PHR } \\
\text { High SC } \\
(n=965)\end{array}$ & & $\begin{array}{c}\text { Low PHR } \\
\text { Low SC } \\
(n=1313)\end{array}$ & \\
\hline $\begin{array}{l}\text { Problem } \\
\text { Behaviors/Experiences }\end{array}$ & OR $(95 \% \mathrm{CI})$ & $p$ & OR $(95 \% \mathrm{CI})$ & $p$ & OR $(95 \% \mathrm{CI})$ & $p$ & OR $(95 \% \mathrm{CI})$ & $p$ \\
\hline $\begin{array}{l}\text { Substance use anywhere } \\
\text { 1. Cigarettes }{ }^{\mathrm{a}} \\
\text { 2. Alcohol }{ }^{\mathrm{a}} \\
\text { 3. Marijuana }{ }^{\mathrm{a}} \\
\end{array}$ & - & - & $\begin{array}{l}1.1(0.7-1.6) \\
1.2(0.8-1.7) \\
1.3(0.9-2.0) \\
\end{array}$ & $\begin{array}{l}.770 \\
.419 \\
.158 \\
\end{array}$ & $\begin{array}{l}0.2(0.1-0.3) \\
0.4(0.3-0.6) \\
0.4(0.3-0.6)\end{array}$ & $\begin{array}{l}.000 \\
.000 \\
.000\end{array}$ & $\begin{array}{l}0.4(0.3-0.7) \\
0.6(0.4-0.9) \\
0.5(0.4-0.8)\end{array}$ & $\begin{array}{l}.000 \\
.000 \\
.002 \\
\end{array}$ \\
\hline $\begin{array}{l}\text { Substance use at school } \\
\text { 4. Cigarettes } \\
{ }^{\text {a }} \\
\text { 5. Alcohol } \\
\text { 6. Marijuana } \\
{ }^{a}\end{array}$ & - & - & $\begin{array}{l}1.8(1.0-3.2) \\
1.4(0.9-2.2) \\
1.7(1.0-2.9)\end{array}$ & $\begin{array}{l}.007 \\
.190 \\
.050\end{array}$ & $\begin{array}{l}0.2(0.1-0.4) \\
0.2(0.1-0.3) \\
0.2(0.1-0.4)\end{array}$ & $\begin{array}{l}.000 \\
.000 \\
.000\end{array}$ & $\begin{array}{l}0.4(0.2-0.8) \\
0.5(0.3-0.7) \\
0.5(0.3-0.8)\end{array}$ & $\begin{array}{l}.011 \\
.001 \\
.008\end{array}$ \\
\hline $\begin{array}{l}\text { Victimization at school } \\
\text { 7. Physical } \\
\text { 8. Relational } \\
\text { 9. Property } \\
\end{array}$ & $\begin{array}{l}- \\
- \\
\end{array}$ & - & $\begin{array}{l}1.5(1.0-2.1) \\
0.9(0.6-1.3) \\
1.3(0.9-1.9) \\
\end{array}$ & $\begin{array}{l}.045 \\
.623 \\
.245\end{array}$ & $\begin{array}{l}0.5(0.4-0.8) \\
0.4(0.3-0.6) \\
0.6(0.4-0.8)\end{array}$ & $\begin{array}{l}.000 \\
.000 \\
.003\end{array}$ & $\begin{array}{l}0.6(0.4-0.8) \\
0.3(0.2-0.5) \\
0.6(0.4-0.8)\end{array}$ & $\begin{array}{l}.003 \\
.000 \\
.018 \\
\end{array}$ \\
\hline $\begin{array}{l}\text { Aggression-related } \\
\text { behaviors at school } \\
\text { 10. Physical fight } \\
\text { 11. Gun } \\
\text { 12. Other weapon }\end{array}$ & - & - & $\begin{array}{l}1.5(0.9-1.9) \\
2.0(0.6-3.7) \\
1.1(0.7-1.7)\end{array}$ & $\begin{array}{l}.033 \\
.032 \\
.748\end{array}$ & $\begin{array}{l}0.4(0.3-0.6) \\
0.2(0.1-0.4) \\
0.2(0.1-0.4)\end{array}$ & $\begin{array}{l}.000 \\
.000 \\
.000\end{array}$ & $\begin{array}{l}0.7(0.4-1.0) \\
0.5(0.3-1.0) \\
0.5(0.3-0.8)\end{array}$ & $\begin{array}{l}.033 \\
.041 \\
.001\end{array}$ \\
\hline
\end{tabular}

Note. ${ }^{\mathrm{a}}$ Psychological Health Risk (PHR; Low BESS $=T$-scores $\leq 60$, High BESS $=T$-scores $\left.\geq 61\right) .{ }^{\mathrm{b}}$ School Connectedness $(\mathrm{SC}$; Low School Connectedness $=$ raw scores $\leq 19$ on the RYDM-SS scale, High School Connectedness $=$ raw scores $\geq 20$ on the RYDM-SS scale). 
Table 4. Odds ratios of risk-related behaviors and experiences by psychological health risk and perceived school connectedness as a promotive factor (Low PHR-High SC set to be the comparison group)

\begin{tabular}{|c|c|c|c|c|c|c|c|c|}
\hline \multirow[b]{3}{*}{$\begin{array}{l}\text { Problem } \\
\text { Behaviors/Experiences }\end{array}$} & $\begin{array}{l}\text { Low PHR } \\
\text { High SC } \\
(n=965)\end{array}$ & & $\begin{array}{c}\text { Low PHR } \\
\text { Low SC } \\
(n=1313)\end{array}$ & & $\begin{array}{l}\text { High PHR } \\
\text { High SC } \\
(n=150)\end{array}$ & & $\begin{array}{l}\text { High PHR } \\
\text { Low SC } \\
(n=554)\end{array}$ & \\
\hline & \multicolumn{8}{|l|}{$\begin{array}{l}\text { Comparison group } \\
\text { Promotive } \\
\text { potential }\end{array}$} \\
\hline & OR $(95 \% \mathrm{CI})$ & $p$ & OR $(95 \% \mathrm{CI})$ & $p$ & OR $(95 \% \mathrm{CI})$ & $p$ & OR $(95 \% \mathrm{CI})$ & $p$ \\
\hline \multicolumn{9}{|l|}{ Substance use anywhere } \\
\hline 1. Cigarettes ${ }^{a}$ & - & - & $2.0(1.5-2.7)$ & .000 & $4.4(2.8-6.9)$ & .000 & $4.7(3.4-6.5)$ & .000 \\
\hline 2. Alcohol ${ }^{\mathrm{a}}$ & - & - & $1.4(1.2-1.7)$ & .000 & $2.2(1.6-3.2)$ & .000 & $2.6(2.1-3.2)$ & .000 \\
\hline 3. Marijuana ${ }^{a}$ & - & - & $1.4(1.1-1.8)$ & .007 & $2.6(1.7-3.9)$ & .000 & $3.5(2.7-4.5)$ & .000 \\
\hline \multicolumn{9}{|l|}{ Substance use at school } \\
\hline 4. Cigarettes ${ }^{a}$ & - & - & $2.6(1.5-4.7)$ & .001 & $5.4(2.8-12.8)$ & .000 & $10.5(6.0-18.5)$ & .000 \\
\hline 5. Alcohol ${ }^{\mathrm{a}}$ & - & - & $2.4(1.6-3.5)$ & .000 & $5.1(3.0-8.9)$ & .000 & $7.0(4.8-10.4)$ & .000 \\
\hline 6. Marijuana ${ }^{a}$ & - & - & $2.1(1.4-3.1)$ & .001 & $4.2(2.3-7.6)$ & .000 & $7.1(4.7-10.8)$ & .000 \\
\hline \multicolumn{9}{|l|}{ Victimization at school } \\
\hline 7. Physical & - & - & $1.1(0.9-1.3)$ & .585 & $1.8(1.3-2.6)$ & .001 & $2.7(2.1-3.4)$ & .000 \\
\hline 8. Relational & - & - & $.83(0.7-1.0)$ & .045 & $2.5(1.8-3.6)$ & .000 & $2.3(1.8-2.8)$ & .000 \\
\hline 9. Property & - & - & $1.1(0.9-1.4$ & .219 & $1.8(1.2-2.7)$ & .003 & $2.3(1.8-2.9)$ & .000 \\
\hline \multicolumn{9}{|l|}{$\begin{array}{l}\text { Aggression-related } \\
\text { behaviors at school }\end{array}$} \\
\hline 10. Physical fight & - & - & $1.6(1.3-2.0)$ & .000 & $2.4(1.6-3.6)$ & .000 & $3.7(2.9-4.7)$ & .000 \\
\hline 11. Gun & - & - & $2.6(1.5-4.6)$ & .001 & $5.2(2.4-11.2)$ & .000 & $10.4(6.0-17.9)$ & .000 \\
\hline 12. Other weapon & - & - & $2.2(1.6-3.1)$ & .000 & $4.6(2.8-7.5)$ & .000 & $5.0(3.5-7.0)$ & .000 \\
\hline
\end{tabular}

Note. ${ }^{\mathrm{a}}$ Psychological Health Risk (PHR; Low BESS $=T$-scores $\leq 60$, High BESS $=T$-scores $\geq 61$ ). ${ }^{\mathrm{b}}$ School Connectedness (SC; Low School Connectedness $=$ raw scores $\leq 19$ on the RYDM-SS scale, High School Connectedness $=$ raw scores $\geq 20$ on the RYDM-SS scale). 


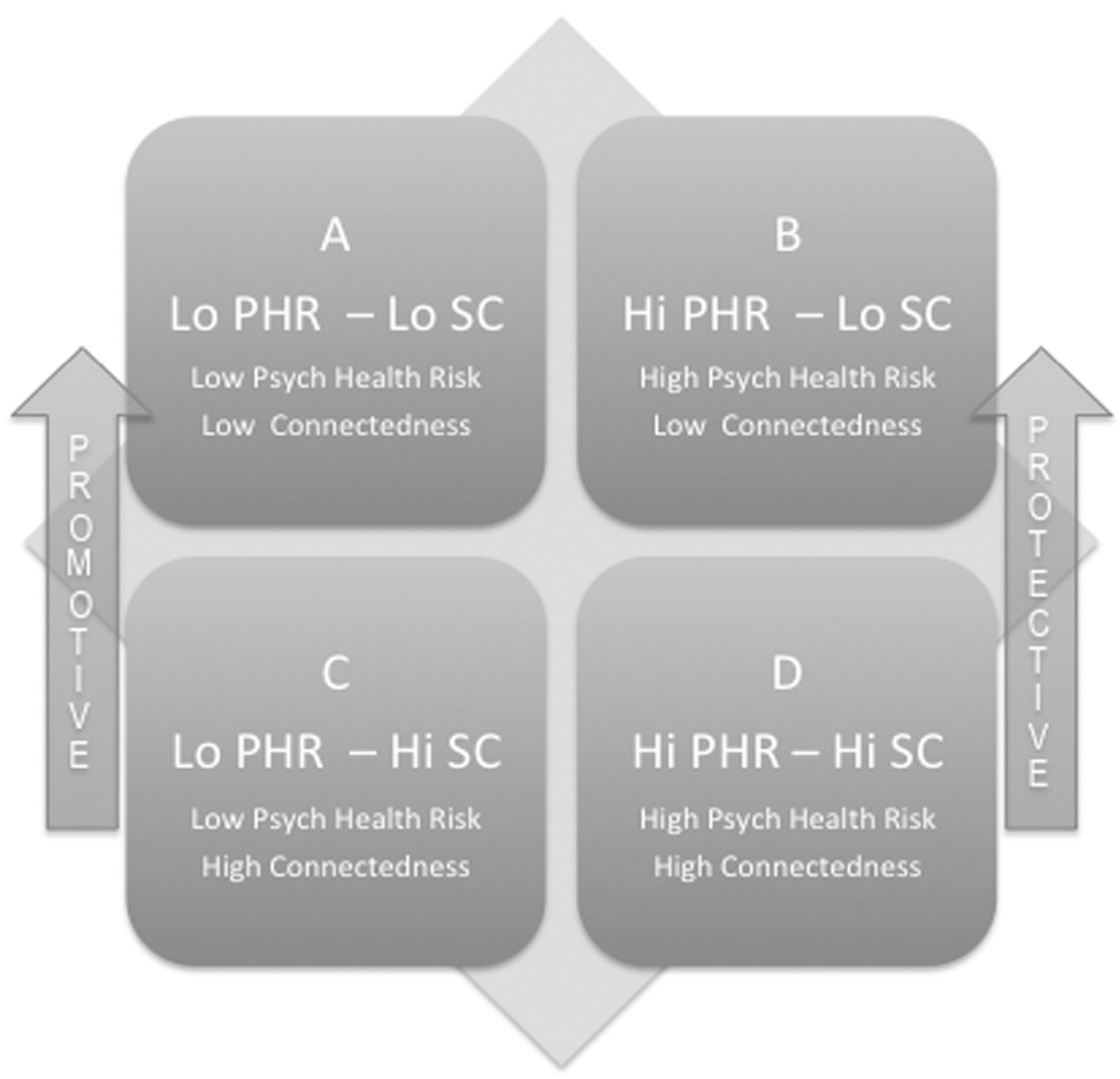

Figure 1. Promotive and protective potential comparison groups

Note. Groups formed by crossing high and low scores on psychological health risk and school connectedness measures Promotive potential is tested by lower rates of problem behaviors/experiences for $\mathrm{C}$ than A. Protective potential is tested by lower rates of problem behaviors/experiences for $\mathrm{D}$ than $\mathrm{B}$.

\section{Appendix: California Healthy Kids Survey Items}

Substance use anywhere

Item stem: During the past $\underline{30 \text { davs }}$, on how many days did you use...

Response options: 0 days, 1 day, 2 days, 3-9 days, 10-19 days, 20-30 days

Scoring for this study: $0=0$ days, $1=1$ or more days

Item: cigarettes?

Item: at least one drink if alcohol?

Item: marijuana (pot, weed, hash, bud)?

Substance use at school

Item stem: During the past $\underline{\mathbf{3 0} \text { davs }}$, on how many days did you use... 
Response options: 0 days, 1 day, 2 days, 3-9 days, 10-19 days, 20-30 days

Scoring for this study: $0=0$ days, $1=1$ or more days

Item: smoke cigarettes?

Item: have at least one drink if alcohol?

Item: smoke marijuana?

Aggression-related victimization

Item stem: During the past 12 months, how many times on school property have you...

Response options: 0 times, 1 time, 2 to 3 times, 4 or more times

Scoring for this study: $0=0$ times, $1=1$ or more times

Item: been pushed, shoved, slapped, hit, or kicked by someone who wasn't just kidding around?

Item: had mean rumors or lies spread about you?

Item: had your property stolen or deliberately damaged, such as your car, clothing, or books?

\section{Aggression-related behaviors}

Item stem: During the past $\underline{\mathbf{1 2} \text { months}}$, how many times on school property have you ...

Response options: 0 times, 1 time, 2 to 3 times, 4 or more times

Scoring for this study: $0=0$ times, $1=1$ or more times

Item: been in a physical fight?

Item carried a gun?

Item: carried any other weapon (such as a knife or club)?

\section{School Support subscale}

Item stem: At my school, there is a teacher or some other adult ...

Response options: $1=$ not at all true, $2=$ a little true, $3=$ pretty much true, $4=$ very much true

Scoring for this study: sum of responses, range $6-24$

13. who really cares about me.

14. who tells me when I do a good job.

15. who notices when I'm not there.

16. who always wants me to do my best.

17. who listens to me when I have something to say.

18. who believes that I will be a success. 